\title{
EGR1 controls divergent cellular responses of distinctive nucleus pulposus cell types
}

\author{
Guus G. H. van den Akker ${ }^{1,2,5}$, Don A. M. Surtel', Andy Cremers', Martijn F. G. A. Hoes², Marjolein M. Caron', \\ Stephen M. Richardson ${ }^{3}$, Ricardo Rodrigues-Pinto ${ }^{3,6}$, Lodewijk W. van Rhijn ${ }^{1}$, Judith A. Hoyland ${ }^{3,4+}$, \\ Tim J. M. Welting ${ }^{1+}$ and Jan Willem Voncken ${ }^{2^{*}+}$
}

\begin{abstract}
Background: Immediate early genes (IEGs) encode transcription factors which serve as first line response modules to altered conditions and mediate appropriate cell responses. The immediate early response gene EGR1 is involved in physiological adaptation of numerous different cell types. We have previously shown a role for EGR1 in controlling processes supporting chondrogenic differentiation. We recently established a unique set of phenotypically distinct cell lines from the human nucleus pulposus (NP). Extensive characterization showed that these NP cellular subtypes represented progenitor-like cell types and more functionally mature cells.

Methods: To further understanding of cellular heterogeneity in the NP, we analyzed the response of these cell subtypes to anabolic and catabolic factors. Here, we test the hypothesis that physiological responses of distinct NP cell types are mediated by EGR1 and reflect specification of cell function using an RNA interference-based experimental approach.

Results: We show that distinct NP cell types rapidly induce EGR1 exposure to either growth factors or inflammatory cytokines. In addition, we show that mRNA profiles induced in response to anabolic or catabolic conditions are cell type specific: the more mature NP cell type produced a strong and more specialized transcriptional response to IL-1 $\beta$ than the NP progenitor cells and aspects of this response were controlled by EGR1.

Conclusions: Our current findings provide important substantiation of differential functionality among NP cellular subtypes. Additionally, the data shows that early transcriptional programming initiated by EGR1 is essentially restrained by the cells' epigenome as it was determined during development and differentiation. These studies begin to define functional distinctions among cells of the NP and will ultimately contribute to defining functional phenotypes within the adult intervertebral disc.
\end{abstract}

Keywords: Intervertebral disc, Nucleus pulposus, Cell line, EGR1, Specific cell responses, IL-1 $\beta$, Inflammation, Differentiation

\section{Background}

Cell models provide valuable tools to study important aspects of cell and tissue biology, including development, differentiation and physiological adaptation to changes in the cellular environment. Such micro-environmental changes include mitogenic or differentiation stimuli, cellcell and cell-extracellular matrix (ECM) contacts or

\footnotetext{
* Correspondence: w.voncken@maastrichtuniversity.nl

${ }^{\dagger}$ Equal contributors

2Department of Molecular Genetics, Maastricht University Medical Centre,

Maastricht, The Netherlands

Full list of author information is available at the end of the article
}

exposure to catabolic factors such as inflammatory cytokines. Despite their close resemblance to cells in their native tissue environment, primary cell models often have restricted application due to their limited proliferative capacity, cellular heterogeneity and poor definition of appropriate culturing conditions. Combined, these factors will cause any physiological response in primary isolates to be an average of multiple, potentially different, responses by a variety of cell types. As such immortal cell lines provide powerful tools to explore isolated cell biology under normal and pathological conditions. 
Cells of the nucleus pulposus (NP) and annulus fibrosus (AF), the two main tissues that form the structure of the intervertebral disc (IVD), are responsible for IVD homeostasis. The gelatinous NP mediates central absorption of mechanical forces, whereas the surrounding fibrous AF secures the positioning of the NP and connects the IVD to the adjacent endplates and vertebra [1]. Human beings will develop some degree of lower back pain and/or degenerative disc disease (DDD) as they age [2]. DDD is associated with aberrant IVD cell function, reduced cellularity and concomitant loss of proteoglycans and tissue dehydration [3]. Although IVD cells play an important role in DDD, to date, knowledge on the exact nature and involvement of different NP and AF cell types in IVD development and DDD is far from complete. Development of the AF is closely related to definition of somites during embryogenesis, whereas a growing number of reports support the notion that all mature NP cells are derived from notochordal precursor cells $[4,5]$. In humans, the presence of cells that express Brachyury $T(T)$ sets apart a progenitor-like notochordal cell (NC) type. As these NC cells disappear during adolescence, the human IVD differs considerably from the IVD in other species, which appears to retain a low percentage of NC cells [1].

Cellular heterogeneity in the human NP is poorly understood. Accumulating evidence from in vivo and in vitro experimental observations, suggests that the mature NP comprises multiple cellular subtypes [6-10]. Although little is known about these NP cell subpopulations this cellular heterogeneity may reflect cellular differentiation stages. The application of human IVD-derived cell material as a potential source of cell lines has been limited, with few studies reporting immortalized IVD cell models [9, 11]. Despite the restricted availability of immortal IVD cell lines, such models can provide important experimental tools to study essential aspects of IVD biology, ranging from the tracking of developmental origins of the NP and AF by marker gene expression to defining cellular targets in DDD. A detailed understanding of ontogenic, cellular and molecular characteristics of IVD cell populations will be valuable to increase our understanding of the contribution of such cells to DDD, for targeted drug development, drug testing for DDD, and ultimately for the development of cell replacement therapies and IVD regeneration.

We recently set out to generate and characterize immortal human NP and AF clonal cell lines $[6,12]$. The main aim of these studies was to determine whether cellular heterogeneity was reflected in the immortalized pool of NP or AF cells. Importantly, the immortalization procedure appeared to have fixed distinctive cellular phenotypes: distinctive NP and AF cellular subtypes were distinguished based on morphological characteristics, on the basis of specific gene and/or protein expression profiles and their response to specific culturing and/or differentiation conditions $[6,12]$. Hence, increased insight in composition of the NP cell population may help define their involvement in pivotal aspects of NP development, maintenance and disease.

Immediate early response genes (IEG) comprise a larger family of responder genes that provide an essential link between the micro-environment of a cell and its physiology. IEGs encode transcription factors that govern genomic responses to altered demands, thereby enabling phenotypic plasticity. Despite their well-established involvement in relaying mitogenic and stress responses, relatively little is known about the involvement of IEGs in skeletal development and homeostasis. The Early Growth Response gene 1 (EGR1; KROX-24; NGFI-A; TIS8; ZIF-268; $Z E N K)$ has been functionally associated to biological aspects of mesodermal derivatives (adipogenesis and tenogenesis), yet relatively little is known about its function in the IVD [13-15]. We recently established that the IEG EGR1 mediates early chondrogenic responses of ATDC5 cells upon exposure to differentiation conditions in vitro [16]. In addition, EGR1 has been associated with acute inflammatory and regenerative responses [17-22]. Thus EGR1 may fulfill a number of crucial tasks at the cross roads of physiological, inflammatory and regenerative responses in the IVD.

We here outline a study that begins to examine the involvement of EGR1 in cell type specific responses of distinct NP subtypes to anabolic and catabolic stimuli. By ablating EGR1 function using RNA interference, we find that EGR1 mediates functionally distinct responses in these NP cellular subtypes. The impact of these findings on understanding NP cellular heterogeneity is discussed.

\section{Methods}

Intervertebral disc cells, cell culture and immortalization

The generation of immortal non-degenerate healthy disc cells has been described elsewhere [6]. Immortalized NP cells were cultured in maintenance medium (DMEM-F12/ Glutamax (Gibco), 10 \% fetal calf serum (FCS; Biowhittaker, cat no DE14-801 F), 1 \% penicillin/streptomycin (Gibco), $1 \%$ non-essential amino acids (NEAA; (Gibco)). Cells were maintained by 1:4 splits (1 passage equals 2 population doublings) seeded at a density of 30,000 cells/ $\mathrm{cm}^{2}$. Unless stated otherwise, representative AF (AF-123) and NP (NP-nR105; NP-R115) clones are utilized for experimentation in this study. Disc material was obtained as surplus material from correction surgery (Medical Ethical Review Committee approval 08-4-021) [6].

\section{Growth factors}

Cells were seeded in monolayer $(8000$ cells/cm2) in basal medium. At day 2, medium was aspirated and cells were washed twice with PBS. Cells were cultured (3 independent 
experiments) for 2 days in Differentiation Medium (DMEM/F12 + $1 \%$ Pen/Strep + $1 \%$ NEAA + $1 \%$ ITS + $1 \%$ ascorbate) containing: no growth factor (control), TGF 33 (10 ng/ml, Life technologies), GDF6 (100 ng/ml, Peprotech), CTGF (100 ng/ml, Peprotech), Il-1 $\beta$ (10 ng/ml, Peprotech) and TNF $\alpha$ (50 ng/ml, Peprotech).

\section{RNA-interference based EGR1 knock-down}

The sense siRNA sequence for human EGR1 was 5'ACGACAGCAGUCCCAUUUATT-3' and the anti-sense sequence was 5 '-UAAAUGGGACUGCUGUCGUTT-3'. A scrambled siRNA-duplex was used as control; both sequences were designed using algorithms provided by the vendor (Eurogentec). IVD cell lines were seeded at 20,000 cells $/ \mathrm{cm}^{2}$ and transfection with siRNAs was performed using ICAfectin 442 (Eurogentec) according to manufacturers' instructions. Procedures were essentially as described before $[16,23]$. Cells were cultured for $16 \mathrm{~h}$ following siRNA transfection before stimulations were performed. EGR1 siRNA concentration was optimized at 30 $\mathrm{nM}$ in parallel in murine and human cell lines (Additional file 1: Figure S1A, B). Sustained EGR1 knock-down at $16+$ $48 \mathrm{~h}$, was verified in ITS-treated NP cells (Additional file 1: Figure $\mathrm{S} 1 \mathrm{C})$.

\section{RNA isolation and quantitative real time PCR}

For RNA isolation, cells were disrupted in Trizol (Invitrogen). RNA isolation, RNA quantification (UV)-spectrometry (Nanodrop, Thermo Scientific), and cDNA synthesis were performed as described before [20]. Realtime quantitative PCR (RT-qPCR) was performed using Mesagreen qPCR master mix plus for $\mathrm{SYBR}^{\bullet}$ Green
(Eurogentec). Validated primer sets used are depicted in Table 1. An Applied Biosystems ABI PRISM 7700 Sequence Detection System was used for amplification: initial denaturation $95{ }^{\circ} \mathrm{C}$ for $10 \mathrm{~min}$, followed by $40 \mathrm{cy}$ cles of DNA amplification. Data were analyzed using the standard curve method and normalized to Cyclophillin B (Cyclo).

\section{Protein extraction and immunoblotting}

Protein extraction and immunoblotting were performed and analyzed as described previously with minor adjustments [21]. For extraction, cells were lysed in RIPA buffer (50 mM Tris pH 8.0, $150 \mathrm{mM}$ $\mathrm{NaCl}, 0.1 \%$ SDS, $5 \mathrm{mM}$ EDTA, $0.5 \% \mathrm{w} / \mathrm{v}$ Sodium Deoxycholate, and $1 \%$ NP-40) supplemented with protease and phosphatase inhibitor (Roche). Lysates were sonicated on ice using the Soniprep $150 \mathrm{MSE}$ at amplitude 10 for 14 cycles ( $1 \mathrm{~s}$ on/ $1 \mathrm{~s}$ off $)$. Insoluble material was removed by centrifugation $\left(10 \mathrm{~min}, 16000 \times \mathrm{g}, 4^{\circ} \mathrm{C}\right)$. Protein concentration was determined using a BCA protein assay kit (Pierce/Thermo Fisher Scientific). Proteins samples were separated by SDS-PAGE and immobilized on Nitrocellulose membranes. Membranes were blocked (1 h, $5 \%$ non-fat dry milk powder (Campina), ambient temp), and incubated with primary antibodies (overnight, $4{ }^{\circ} \mathrm{C}$ ). Antisera: mouse monoclonal EGR1 (Abcam 55160), rabbit polyclonal $\beta$-Actin (C4, 691001; MP Biomedicals), Secondary antisera: rat anti-mouse (P0260; DAKO, Glostrup, Denmark) and donkey antirabbit (711035-152; Jackson Lab, Bar Harbor, ME, USA). Signals were detected using enhanced chemoluminescence (Pierce).

Table 1 rtPCR primer sets for gene expression measurements

\begin{tabular}{lll}
\hline Symbol & Forward primer & Reverse primer \\
\hline ADAMTS4 & GGTCATGTCTTCAACATGCTCC & AGGATCCACATGAGCCATCAC \\
COL1A1 & TGGAGAGTACTGGATTGCCCC & TGCAGAAGACTTGATGGCATC \\
COL2A1 & TGGGTGTTCTATTATTATTGTCTTCCT & GCGTTGGACTCACACCAGTTAGT \\
COX2 & ACCAACATGATGTTGCATTCTT & GGTCCCCGCTTAAGATCTGTCT \\
EGR1 & TGACCGCAGAGTCTTICCT & TGGGTTGGTCATGCTCACTA \\
KRT19 & GCAGTCACAGCTGAGCATGAA & TCCGTTCTGCCAGTGTGTCT \\
MMP3 & TGATGAACAATGGACAAAGGATACA & TाTCATGAGCAGCAACGAGAA \\
SOX9 & AGTACCCGCACCTGCACAAC & CGCTTCTCGCTCTCGTTCAG \\
T & CCACCTGCAAATCCTCATCCT & TTGGAGAATTGTTCCGATGAG \\
TNFa & TCAATCGGCCCGACTATCTC & CAGGGCAATGATCCCAAAGT \\
VCAN & TCCCTCACTGTGGTCAAG & GTGTGTACCTGCTGGTTG \\
BACT & CCTGGCACCCAGCACAAT & GCCGATCCACACGGAGTACT \\
CYCLO & CCTGCTTCCACCGGATCAT & CGTTGTGCGCGTAAAGTC \\
EIF2B1 & TGTCAGGTAAGAAATGGCCAAA & TGTAGCCGACAGCAGCATCT \\
MRPL19 & CGCCGAAACCGGTCATC & TCCCCTTCGAGGAATGAATTC \\
\hline
\end{tabular}




\section{Immunohistochemistry}

Research involving human material was performed in accordance with the Declaration of Helsinki. Human IVD tissue for histology was obtained from a 63 years old deceased (non-heart beating) donor. Approval for all experimental sections of the current study and informed consent for publication of patient details and accompanying images in this manuscript was obtained as an integral part of the MUMC-Medical Ethical Review Committee (METC approval 08-4-021; July 11, 2012); the approval is held by the authors (LWvR) and is available for review by the Editor-in-Chief. Two lumbar IVDs L1/2 (without overt signs of degeneration; healthy) and L4/L5 (clearly degenerated) were dissected by an orthopedic surgeon. Tissue was isolated, fixed in formalin and decalcified in 0.5 M EDTA pH 7.8 for two weeks. EDTA was refreshed every two days. Tissues were dehydrated and embedded in paraffin and five micrometer section were cut and positioned on Superfrost Plus slides. For immunohistochemical analysis, sections were deparaffinized and rehydrated using standard protocols. Antigen retrieval was performed in hot citrate buffer $(1.8 \mathrm{mM}$ citric acid and $8.2 \mathrm{mM}$ tri-sodium citrate), endogenous peroxidase activity was inactivated by Peroxidase-Blocking solution (Dako, REAL) and samples were blocked with $10 \%$ normal sheep serum. Rabbit polyclonal anti-Egr-1 (Santa Cruz Biotechnology) was incubated overnight at $4{ }^{\circ} \mathrm{C}$ in 1:200 concentration (primary antibody was not used for negative control sections). Unbound antibodies were removed by washing in PBS with $0.1 \%$ Tween. Bound primary antibodies were detected with HRP-labelled antirabbit secondary antibodies (EnVision + System-HRP labelled Polymers; Dako) by incubation for $30 \mathrm{~min}$ at room temperature. For detection, DAB chromogen substrate (Dako) was used. Stained sections were counterstained with Mayor's Hematoxylin (Dako) and subsequently dehydrated and mounted in Histomount (Thermo Shandon) for microscopic analysis.

\section{Statistics}

Statistical significance $(p<0.05)$ was determined by twotailed Student's $t$-test. To test for normal distribution of input data, D'Agostino-Pearson omnibus normality tests were performed. All quantitative data sets presented passed the normality tests. Gene expression analyses show mean and standard deviation (as indicated); indicated $p$-values in figures represent the comparison between AF and NP for all donors combined or between clonal subtypes (NP-R vs NP-nR).

\section{Results}

Differentiation induces EGR1 in IVD cells

A detailed description of the NP cellular subtypes used in the current study is published elsewhere [6]. We have previously established that chondrogenic ATDC5 cells strongly induce EGR1 mRNA and protein expression in response to chondrogenic differentiation stimuli [16]. To investigate whether IVD cells activate EGR1 expression in response to changes in their environment, we initially subjected immortal AF and NP cell lines to previously defined chondrogenic differentiation conditions [16]. Typically, IEG expression in most cell types is low or absent under basal conditions and, upon exposure to differentiation conditions, increases within hours at the mRNA and protein levels. Basal EGR1 mRNA expression was approximately 2-4 fold higher in immortal AF cells than in two phenotypically distinct NP cell types of which the NP-R cell type showed the lowest EGR1 mRNA levels (Fig. 1a). Exposure of these IVD cell types to chondrogenic differentiation conditions resulted in a robust EGR1 mRNA induction ( \pm 6 fold) at $2 \mathrm{~h}$ postinduction in NP-R cells (Fig. 1b; upper panel); the maximum response of NP-nR cells did not reach twofold, whereas AF cells did not show any induction of EGR1 at the $2 \mathrm{~h}$ time point (Fig. 1b, upper panel). Valproic acid (VPA), a known inducer of IEGs [24, 25], was used in a parallel experiment as an intended positive control. VPA exposure resulted in a pronounced upregulation of EGR1 mRNA, although, surprisingly, exclusively in NP$\mathrm{R}$ cells; as with ITS, no EGR1 mRNA induction was detected in NP-nR and AF cells (Fig. 1b, lower panel). The twofold increase of EGR1 mRNA at $8 \mathrm{~h}$ post-induction in NP-nR cells was significant, but did not qualify as an IEG response.

We next examined EGR1 induction at the protein level. EGR1 protein was detectable in vitro at relatively low levels in all three IVD cell types, and was rapidly induced within $2 \mathrm{~h}$ after stimulation with chondrogenic differentiation medium in all cells (Fig. 1c). Despite the poor correlation of basal mRNA and protein levels in these respective cell lines under control conditions, mRNA ( $c f$. Fig. 1b) and protein levels upon stimulation with ITS were consistently highest in the NP-R (responder) clone. This data suggests that upregulation of EGR1 protein in IVD cells is accompanied by an induction of EGR1 mRNA preferentially in NP-R cells. Given that AF cells did not respond, further analysis did not include these cells.

\section{Distinct physiological responses in specialized NP cellular subpopulations}

In a recent report, we speculated that the distinct immortal NP subtypes differ in differentiation/maturation status [6]. This previous data suggested that NP-R cells represent a more progenitor-like phenotype and that NP-nR are more mature, differentiated cells, as they do not produce the robust SOX9 response that NP-R cells show upon exposure to differentiation conditions. In line with this idea, we have previously shown that chondrogenic differentiation of 

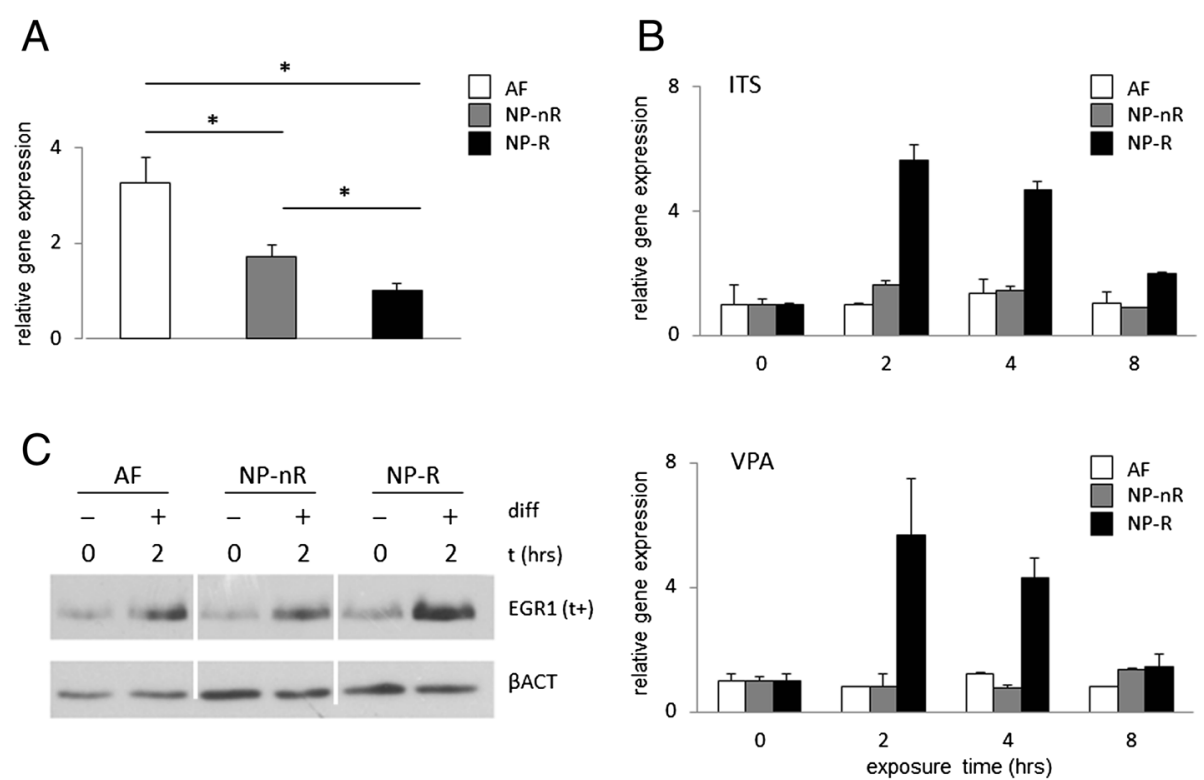

Fig. 1 Induction of EGR1 expression in IVD cell lines. a Basal expression of EGR1 mRNA in representative clones (AF-123, NP-nR 105 and NP-R 115). Gene expression was normalized to Cyclophillin B and is presented relative to the NP-R clone. b Insulin, Transferrin and selenite (ITS; $10 \mu \mathrm{g} / \mathrm{ml}$ insulin, $10 \mathrm{mg} / \mathrm{ml}$ transferrin and $3 \times 10^{-8} \mathrm{M}$ sodium selenite) and Valproic acid $(0.3 \mathrm{mM})$ were used to stimulate IVD cell lines for $0,2,4$ and $8 \mathrm{~h}$. Gene expression of EGR1 was normalized to Cyclophillin $B$ and is presented relative to the $t=0$ time point. Bars represent a biological triplicate. $\mathbf{c}$ Protein expression of EGR1 under basal conditions and in response to stimulation with chondrogenic media for two hours. AF, NP-nR and NP-R samples were run on the same gel to allow direct comparison. The indication ( $\mathrm{t}+$ ) points to a long apposition time. Beta Actin (BACT) was used as loading control; asterisks indicate significantly different expression level; $p<0.05$

ATDC5 cells is critically dependent on EGR1 [16]. Based on these findings we speculated that the distinct NP cellular subtypes may be differentially sensitive to specific physiological stimuli. In line with the above observations, we predicted that NP-R would respond more robustly to differentiation stimuli, whereas NP-nR may be more sensitive to degenerative stimuli. To this end NP-nR and NP-R cells were subjected to anabolic (i.e. growth factors) or catabolic conditions (i.e. inflammatory cytokines), representing potential regenerative or degenerative stimuli, respectively. Transcriptional regulation of a number of marker genes was measured in response to differentiation conditions, among which: KRT19, T (Keratin 19 and Brachyury T), SOX9 (SRY box-9), COL2A1, COL1A1 (type 2 and 1 alpha Collagens) and $V C A N$ (Versican), from here on referred to as IVD marker genes. In addition, expression of a number of catabolic markers, including MMP3 (Matrix Metalloproteinase 3) and ADAMTS4 (A Disintegrin and Metalloproteinase with Thrombospondin motifs 4,5 ) was determined. The biological responses to anabolic or catabolic stimuli showed remarkable differences between NP-R and nR subtypes: overall anabolic conditions (growth factor stimulation) induced expression of the IVD markers SOX9, COL2A1, COL1A1, VCAN, KRT19 and T in NP-R cells (Fig. 2a). Conversely, exposure to different growth factors produced an overall transcriptionally repressive response of IVD marker gene expression in NP-nR cells. This overall effect on transcription of these IVD markers was clearly less unidirectional in NP-R cells. The only conspicuous exception was TGF $\beta 3$-induced COL1A1 and COL2A1 induction in the NP-nR subtype. NP-nR cells showed a massive induction of MMP3 in response to IL- $1 \beta$ or TNF $\alpha( \pm 1000$ fold or 100 fold, respectively), whereas this response was less pronounced in the NP-R clones $( \pm 10-100$ fold less). The ADAMTS4 marker was expressed at similar levels in both NP subtypes in response to IL- $1 \beta$ and was slightly up in the TNF $\alpha$ NP-R cells. This data suggests that, phenotypically distinct NP-R and NP-nR cells also differ in terms of responses to anabolic and catabolic conditions.

\section{EGR1-dependent responses in NP cellular subtypes}

EGR1 has been reported to mediate transcriptional responses to inflammatory cytokines including IL- $\beta[18,19$, $26,27]$. We therefore investigated the EGR1-dependence of the catabolic responses to IL-1 $\beta$, as this cytokine induced clear differences in gene response profiles between NP-R and NP-nR cells. We first examined the EGR1 protein induction in response to IL- $1 \beta$ stimulation in more detail. NP-R and NP-nR cells were exposed to IL- $1 \beta$ for $2 \mathrm{~h}$, and EGR1-induction was compared in whole cell extracts; maintenance medium, differentiation medium or VPA exposed cell extracts $(2 \mathrm{~h})$ were taken as reference conditions. As before, NP cells induced EGR1 protein in response to differentiation conditions. Both NP-nR and NP-R cells 

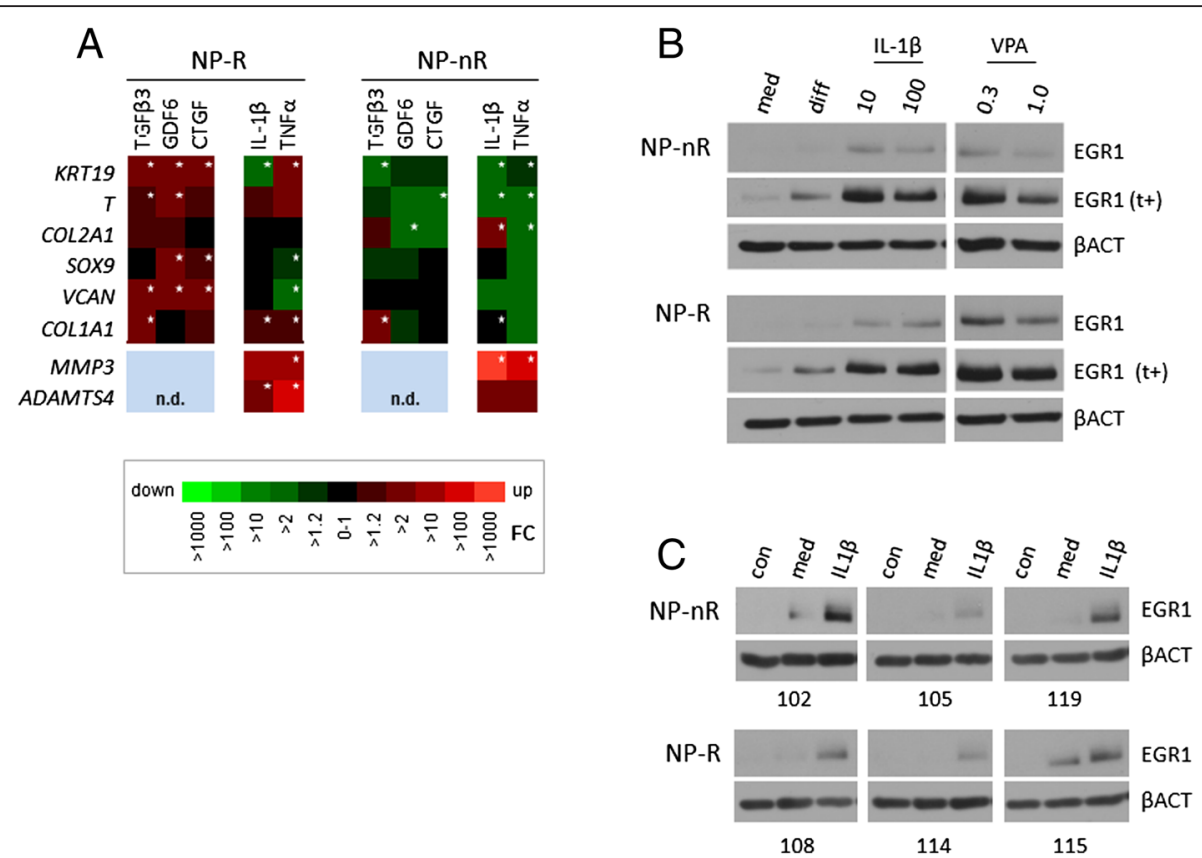

Fig. 2 Cytokines induce catabolic response in the mature NP subclones. a Heatmap representation of gene expression changes in distinct NP subclones. NP cell clones NP-nR 105 and NP-R 124 were stimulated for two days with anabolic factors TGFß3 (10 ng/ml), GDF6 (100 ng/ml), CTGF $(100 \mathrm{ng} / \mathrm{ml})$ or catabolic factors IL-1 $\beta(10 \mathrm{ng} / \mathrm{ml})$ or TNFa $(50 \mathrm{ng} / \mathrm{ml})$. mRNA levels for the following genes was determined: KRT19, T, COL2A1, SOX9, VCAN, COLIA1, MMP3 and ADAMTS4. Gene expression was normalized to the average of EIF2B1 and MRPL19 expressions. Fold induction was calculated by comparison to untreated cells at day 2 and is represented in a heatmap; $n$.d.: not determined. Asterisks indicate significantly different expression level; $p<0.05$. b Protein expression of EGR1 in response to maintenance medium (med), differentiation medium (diff), IL-1 (10 and $100 \mathrm{ng} / \mathrm{ml}$ ) or Valproic acid (0.3 and $1 \mathrm{mM}$ ). NP-nR 105 and NP-R 115 samples were run on the same gel to allow direct comparison. The indication $(\mathrm{t}+)$ points to relatively long apposition times. B Actin was used as loading control. c Three NP-nR and three NP-R clones were either left undisturbed (con), exposed to a change of maintenance medium (med) or medium supplemented with $\mathrm{LL}-1 \beta(10 \mathrm{ng} / \mathrm{ml})$ for two hours. Non-stimulated cells at time point $t=0$ were used as control (con). Beta Actin ( $\beta A C T$ ) was used as loading control

produced an obvious EGR1 induction in response to either 10 or $100 \mathrm{ng} / \mathrm{mL}$ IL-1 $\beta$ (Fig. 2b). We evaluated IL-1 $\beta$ induced EGR1 response in multiple independent NP-nR and NP-R clones: all clones showed a robust induction of EGR1 protein upon $2 \mathrm{~h}$ of IL-1 $\beta$ treatment (Fig. 2c). Combined, this data shows that both anabolic and catabolic conditions induce an immediate early response in IVD cell types. Combined, our previous observations [6] and the data presented thus far, shows that although EGR1 is induced in both NP cell subtypes by differentiation factors and inflammatory cytokines, their transcriptomic responses are dissimilar.

To further investigate a potential involvement of EGR1 in the transcriptomic response to inflammatory cytokines like IL-1 $\beta$, an siRNA duplex was designed with the aim to reduce cellular EGR1 mRNA and protein levels; a robust knock-down was obtained at EGR1 siRNA concentrations of 30 and $100 \mathrm{nM}$ (Additional file 1: Figure S1A), which was specific for EGR1 as it had no effect on EGR2 and EGR3 mRNA levels (Additional file 1: Figure S1B). NP cells were transiently transfected with either $30 \mathrm{nM}$ siRNA targeting human EGR1 (siEGR1) or a scrambled control siRNA (siCTRL). Cells were treated with IL-1 $\beta 16 \mathrm{~h}$ following transfection, and samples were taken for expression analysis at 2 and $48 \mathrm{~h}$ post-treatment. To verify knockdown throughout the duration of the 2 day induction experiment, EGR1 protein levels were initially compared in SiCTRL or siEGR1 transfected cells at 0,2 and 48 h postITS treatment; this analysis showed a robust and sustained reduction of EGR1 protein at 2 and $48 \mathrm{~h}$ post-treatment (Additional file 1: Figure S1C). Consistent with the transient nature of IEG induction, the EGR1 protein level was markedly increased at $2 \mathrm{~h}$ after IL- $1 \beta$ exposure and had returned to starting $(t=0)$ levels at $48 \mathrm{~h}$ (Fig. 3a). Transfection of NP-R or NP-nR cells with the siEGR1 successfully diminished EGR1 induction at the protein level $2 \mathrm{~h}$ into IL$1 \beta$ treatment, to nearly undetectable levels (Fig. 3a). At $48 \mathrm{~h}$ of IL-1 $\beta$ treatment, EGR1 was neither detectable in the siCTRL nor in the siEGR1-transfected cells. Thus, the siRNA duplex successfully prevented ERG1 induction in response to IL-1 $\beta$ in both NP-R and NP-nR cells. Moreover, the absence of EGR1 protein at $48 \mathrm{~h}$ in the siEGR1-condition suggested that the siRNA-mediated targeting strategy did not delay EGR1-induction.

We then examined expression of a number of genes which are known to be induced by inflammatory cytokines 
A

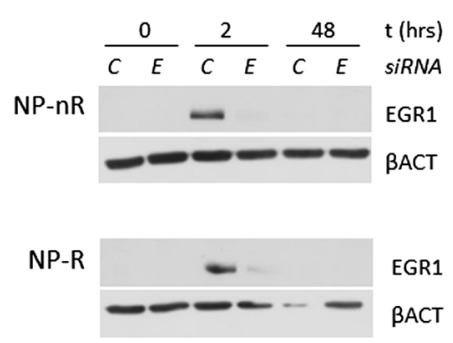

B

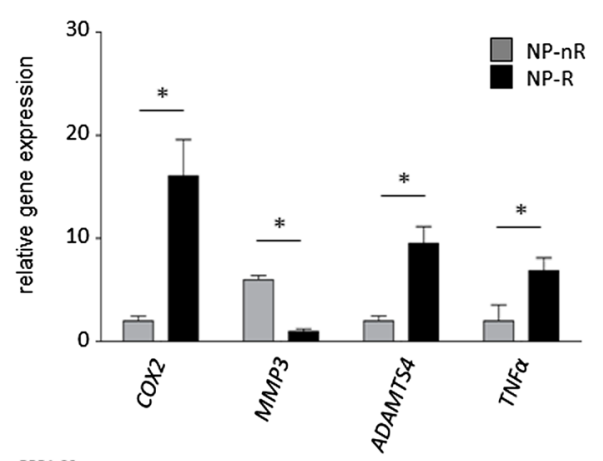

C
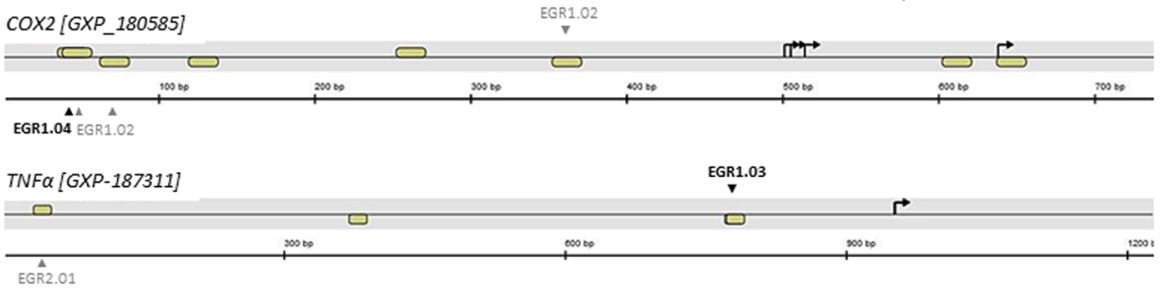

MMP3 [GXP-193549]

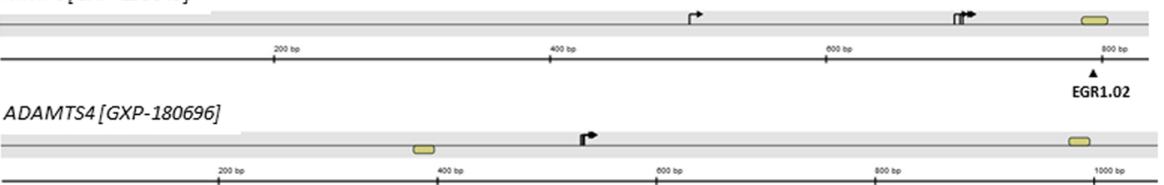

Fig. 3 Confirmation loss of EGR1 function. a NP-nR and NP-R clones were transfected with 30 nM siRNAs targeting EGR1 (E) or control (C) siRNA. Sixteen hours after transfection cells were harvested (time point $\mathrm{t}=0$ ) and stimulated with IL-1 $\beta$ for 2 and $48 \mathrm{~h}$. Immunoblotting for EGR1 reveals efficient knock-down of EGR1 at two hours post stimulation in both cell lines. Beta Actin ( $\beta A C T$ ) was used as loading control. b Basal expression of COX2, TNFa, MMP3, and ADAMTS4 genes implicated in disc degeneration at t0. Gene expression was normalized to Cyclophillin B; asterisks indicate significantly different expression level; $p<0.05$. $\mathbf{c}$ In silico representation of the promotor region of genes implicated in disc degeneration (Genomatix software; http://www.genomatix.de). Putative transcription factor (TF) binding sites for EGR family members are depicted by yellow boxes; highprobability EGR binding sites are indicated by black/bold print arrow heads, low-probability binding sites by light grey/normal print. Black arrows indicate the transcription start site

and for which biological relevance in intervertebral disc degeneration had been shown before [28]. These genes included: COX2, TNF, MMP3 and ADAMTS4. Basal expression measurements in NP-R and NP-nR clones revealed significant differences for all genes: NP-nR cells showed higher basal expression levels for most markers, $M M P 3$ excepted (Fig. 3b). We have previously shown that chondrogenesis is dependent on intrinsic NF- $\mathrm{kB}$ signaling also used by inflammatory cells [23]. In addition, we showed a direct involvement of COX-2 in in vitro and in vivo models for chondrogenesis [29]. We next asked whether expression of COX2, TNF,$M M P 3$ and/or ADAMTS4 was regulated in response to IL-1 $\beta$, and whether their regulation involved EGR1; the latter was tested by comparing cells expression siRNA against EGR1 mRNA (siEGR1) to cells expressing siCTRL (control). The absence or presence of potential EGR family-consensus binding sites in the promoters of the corresponding genes was assessed via www.genomatix.de (Fig. 3c). COX-2, $T N F \alpha$ and $M M P 3$ carried potential EGR1 binding sites, whereas ADAMTS4 did not. COX-2 was neither induced at $\mathrm{t}=2$ nor $\mathrm{t}=48 \mathrm{~h}$ in NP cells, independent of subtype (Fig. 4a). This continued repression of $C O X-2$ expression appeared to be dependent on EGR1 throughout our experimental setting, as $C O X-2$ was massively induced at $48 \mathrm{~h}$ of IL-1 $\beta$ treatment in NP-nR cells $( \pm 60.000$ fold $)$ and in NP-R cells ( \pm 40.000 fold) that lack EGR1.

NP-nR cells initiated a significantly higher TNF $\alpha$ transcription $( \pm 3000-4000$ fold versus $<100$ fold in NP-R cells) in response to IL- $1 \beta$ (Fig. $4 \mathrm{~b}$ ). As for COX2, TNF $\alpha$ expression was negatively controlled by EGR1, as EGR1 knock-down released $T N F \alpha$ mRNA synthesis in both NP cell types at $2 \mathrm{~h}$ of IL-1 $\beta$ treatment, this difference was significant from that of siCTRL cells. TNFa induction in siEGR1 NP-R cells did not approach the high levels observed in NP-nR cells ( \pm 7000 fold versus \pm 1200 fold). $T N F \alpha$ expression appeared to be tightly controlled by EGR1 in the early response phase, as expression ceased at $48 \mathrm{~h}$ and appeared no longer dependent on EGR1. Basal MMP3 gene expression was increased in NP cells 


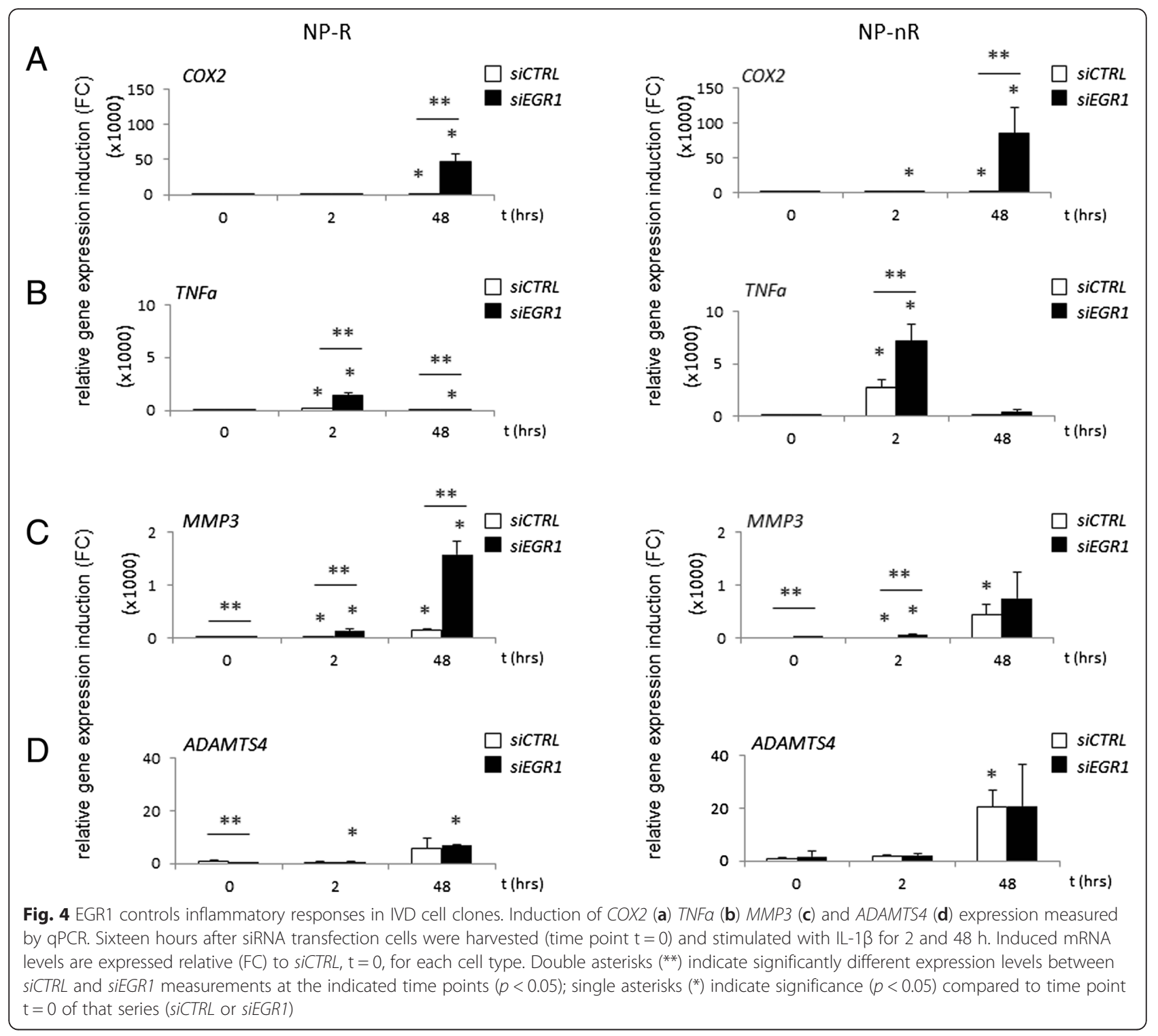

transfected with EGR1 siRNA (Fig. 4c). IL-1 $\beta$ treatment significantly induced $M M P 3$ expression at $2 \mathrm{~h}$ in both cell types. In analogy to the earlier observed more robust induction of MMP3 in NP-nR versus NP-R cells ( $c f$. Fig. 2a), we found that $M M P 3$ followed a similar trend in this experimental setting: IL- $1 \beta$ induced $M M P 3$ mRNA at higher levels in NP-nR siCTRL cells than in NP-R cells at $48 \mathrm{~h}$. Relevantly, in the absence of EGR1 MMP3 expression was strongly induced at $48 \mathrm{~h}$ in NP-R clones. Thus, EGR1 is required to repress inflammatory $M M P 3$ expression stimulation in NP-R clones. Finally, although IL-1 $\beta$ stimulation induced ADAMTS4 expression at $48 \mathrm{~h}$ in both cell-types, expression levels at $48 \mathrm{~h}$ were significantly higher in NP-nR clones, compared to NP-R clones (Fig. 4d). The absence of any effect of EGR1-knock-down on ADAMTS4 mRNA levels in response to IL-1 $\beta$, suggests that ERG1 does not directly regulate ADAMTS4 expression levels and is congruent with the absence of EGR1 binding sites in its promoter.

In summary, the data presented here corroborate the earlier observed differences in gene expression between $\mathrm{NP}-\mathrm{R}$ and NP-nR clones in response to catabolic stimuli. EGR1 appeared to predominantly act repressive on IL$1 \beta$-induced gene expression. For $C O X 2$ and $M M P 3$, this was a late effect, suggesting the involvement of additional, secondary transcriptional factor and/or signaling networks in succession to the initial transient EGR1 response, whereas $T N F \alpha$ induction was repressed at an early response time point, specifically in NP-R.

Thus far the above data show that differentiated/mature NP-nR cells are more responsive to catabolic stimuli than the relatively undifferentiated/progenitor-like 
NP-R cells, and that aspects of both early and maintained gene expression in response to IL- $1 \beta$ are controlled by EGR1. Based on these findings, we speculated that NP cells expressing EGR1 should be detectable in histological sections of degenerate human intervertebral disc material. Indeed, compared to healthy control section, in which approximately $\pm 5 \%$ of cells in the NP showed EGR1 expression, one in three NP cells in degenerate IVD tissue displayed EGR1-positivity (Fig. 5a, b). Taken together, the data presented support the idea that EGR1 is an important biological response factor in NP cells, and that EGR1 expression is increased under degenerate conditions in the human NP.

\section{Discussion}

We here examined a potential role for the immediate early response gene EGR1 in various physiological responses of phenotypically distinct immortalized NP cell types. Our combined data shows that the immortalized NP cellular subtypes respond differentially to anabolic and catabolic stimuli. We also provide evidence that the immediate early response gene product EGR1 is differentially involved in cell type-specific responses to IL- $1 \beta$ in immortalized NPcellular subtypes in vitro. The data presented in this paper thus supports our previous findings that the NP harbors multiple functionally specialized cell types [6].

\section{Distinct biological functions for NP cell types}

Despite the realization that cells in the NP are crucially involved in IVD homeostasis and pathology, little is known about the nature and functionality of such NP cell subpopulations. Several novel lines of evidence support the notion that the NP contains functionally distinct cell types. Recent studies have demonstrated that the NP harbors immature cells with somatic stem celllike properties [8-10]. We previously reported on a unique experimental immortalization approach to address the issue of NP cellular heterogeneity [6]. We were able to show that multiple phenotypically distinct NP cell types could be immortalized and clonally expanded. The fact that these distinct cellular subpopulations could be isolated from independent donors provided robust and crucial confirmation for the heterogeneous nature of the human NP cell population. Cellular heterogeneity in the NP may reflect different stages of proliferation, differentiation and maturation. Our data thus far suggested that NP-R (responder) clones represented a more immature cell type that harbors an intrinsic capacity to respond to chondrogenic differentiation stimuli. In addition this subpopulation spontaneously formed spheroid structures in (pseudo) 3D cultures [6]. NP-nR (non-responder clones), in contrast, did not induce predicted key developmental control (e.g. SOX9) or lineage marker genes (e.g. CA12, FOXF1, COMP) when exposed to chondrogenic conditions and its relatively high membrane-associated CD24 expression suggested that these specific characteristics reflected an ontogenically more advanced stage. To begin to understand the potential biological relevance of these specific NP cell phenotypes, we compared anabolic and catabolic responses of NP-R and NP-nR cells. Our current data show that whereas the NP-R cell response to growth and differentiation factors is substantially more robust than that of NP-nR cells, NP-nR cells, in contrast, appeared to produce a more specialized catabolic response than NP-R cells. Although both cell types display EGR1 induction upon treatment with inflammatory cytokines, the differential transcriptomic response argues that, although the
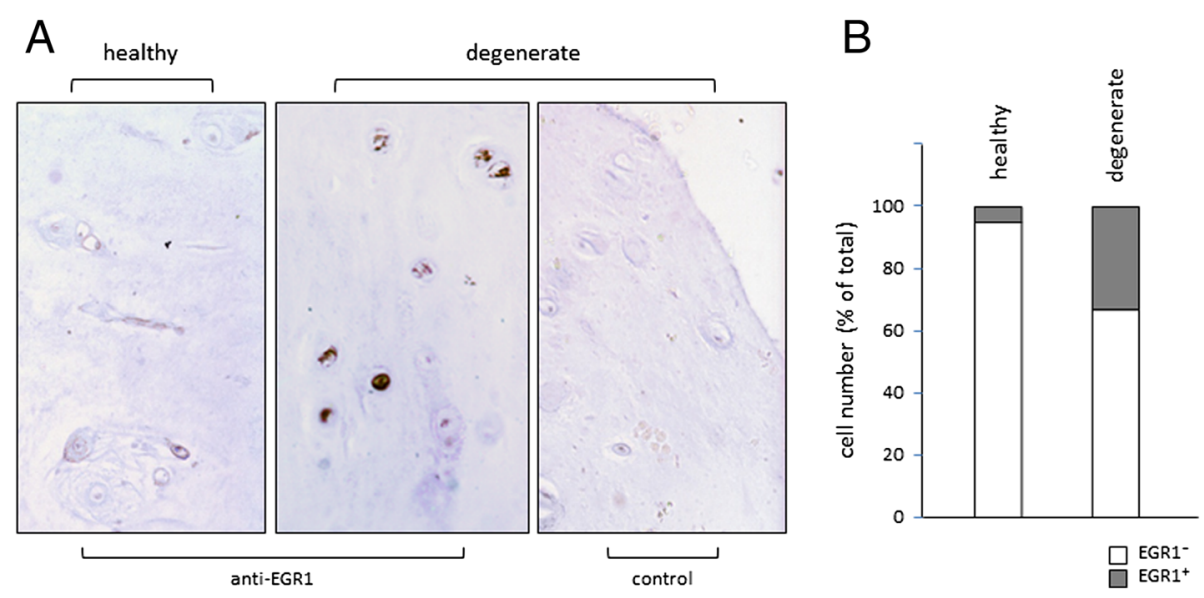

Fig. 5 EGR1 expression is increased in degenerate NP cells. a Immunodetection of EGR1-positive cells in healthy control NP tissue (L1/L2 IVD of a 63 years old donor; left panel) and in degenerate NP tissue (L4/L5 IVD of the same donor middle panel); right panel: staining control on degenerate NP section: primary antiserum detecting EGR1 was left out. $\mathbf{b}$ Quantification of EGR+ cell numbers in healthy or degenerate NP tissue. Cell numbers are depicted as percentage of total cell number scored (total cell counts: 121 for healthy tissue and 218 for degenerate tissue) 
NFкB signaling network in both cell types is operational, the NP-nR may possess a more mature downstream signaling network enabling an EGR1-dependent catabolic response. One striking example thereof is the substantially higher IL-1 $\beta$-induced MMP3 mRNA level in NP$n R$ cells compared to NP-R cells. These findings may be relevant in the context of IVD degeneration: indeed MMPs are involved in DDD [30]. Based on these results it is tempting to speculate that different IVD cell types may have differential contributions to IVD homeostasis and pathology: specific cells maintain homeostasis and harbor potential regenerative capacity, whereas functionally distinct cells may have acquired the ability to respond to inflammatory conditions. CD24-positive NP-nR cells may be sufficiently mature/specialized to partake in catabolic responses to tissue damage, whereas this response would not be beneficial for precursor NP-R cells. Conversely, relatively immature cells would aid in tissue repair, most likely triggered by and/or in response to signals generated by mature cells. In this respect it is interesting to note that IL-1 $\beta$ and TNF $\alpha$ induced a more anabolic profile in the less mature NP-R cells compared to the NP-nR cells (cf. Fig. 2a).

\section{EGR1 regulates NP cell type-specific responses}

Understanding the specific immediate early responses of distinct cell types provides insight into genetic and epigenetic wiring of a given cell system. Immediate early response genes (IEG) mediate signaling between the cellular micro-environment and the nucleus. The IEG response is typically transient and serves to control secondary transcriptional responses by acting as facilitators or repressors of gene expression, in conjunction with other transcriptional regulatory factors [31-36]; this enables cells to mount a quick and physiologically relevant response to changed conditions. Such responses may be anabolic, e.g. during differentiation and development or tissue repair, or catabolic, e.g. during inflammation. We reported before that EGR1 fulfills a crucial early role in preparing ATDC5 cells for replicative amplification and transcriptome remodeling that accompany chondrogenic differentiation [16]. Here we provide evidence that in functionally distinct NP cell types, EGR1 mediates specialized cellular responses to either growth factor stimulation or inflammatory cytokines. The higher induction of EGR1 in NP-R cells may reflect an intrinsic ability to respond more robustly to differentiation conditions than a NP-nR clone [6]. The ability of cells to generate a physiologically appropriate response is dictated by its epigenetic constitution: as a result of lineage commitment and differentiation cells have become epigenetically restricted to function within a given lineage. Although IEGs play crucial roles in helping cells respond to, for instance, differentiation factors, increasing experimental evidence suggests that their main task is to augment rather than initiate gene transcriptional activity $[37,38]$. This ability is at least in part due to their recruitment of Histone Acetyl Transferase (HAT) activity to their transcriptional target sites [39]. Likewise we found that early global histone acetylation failed in EGR1-deficient chondrogenic cells [16]. Moreover, we showed that, despite the presence of consensus EGR1 binding sites, Polycomb-dependent, epigenetically repressive Histone H3 lysine 27 trimethyl (H3K27me3) marking prevented promoter access of EGR1 [16]. We propose that restrictive epigenetic boundaries dictate the cell-specific transcriptomic responses in NP-R cells (more anabolic) versus NP-nR cells (more catabolic). In differentiating ATDC5 cells we were able to show that expression of certain lineage-specific genes (SOX6, AGC) was attained through loss of repressive H3K27me3 marks [16]. It is conceivable that similar epigenetic programming has occurred during maturation of NP-R to NP-nR cells. Although VPA was merely used as a positive response control in the current study, it is interesting to note that NP-R and NP-nR cells also responded differentially to VPA. VPA is known to suppress IEG responses [24, 25]. It is conceivable that the observed differences relate to a relative insensitivity of NP-R cells to VPA (i.e. epigenotype). Involvement of restricted epigenomic vulnerability to VPA may be corroborated by studies that show VPA has teratogenic effects in certain species $[40,41]$ and during defined time windows during embryogenesis [42].

Proteins of the matrix metalloproteinase (MMP) family are involved in the breakdown of extracellular matrix in normal physiological processes, such as embryonic development, reproduction, and tissue remodeling, as well as in disease processes, such as arthritis and metastasis [43-45]. EGR1 was found to mediate TNF $\alpha$-induced MMP9 expression in various cell types [18]. Our data are in line with an early role for TNF $\alpha$ in the catabolic response of NP-nR cells [28], as it is rapidly and exclusively induced by IL-1 $\beta$ in NP-nR cells. Interestingly, EGR1 appears to restrain $T N F \alpha$ expression rather than to augment it. Indeed, EGR1 is known to positively and negatively affect gene expression, through partnerships with transcriptional co-activators or co-repressors [26, 31-33].

Interestingly, both NP cell types do not induce COX2 mRNA in response to IL-1 $\beta$; EGR1 clearly functions to suppress COX2 expression, as both NP-nR and NP-R clones show strong COX2 induction at $48 \mathrm{~h}$ of IL- $1 \beta$ treatment in the absence of EGR1 (60,000 and 40,000 fold, respectively). We previously reported that COX2 expression correlates with hypertrophic differentiation in articular cartilage models and pharmacological inhibition of COX2 decreases hypertrophy [29]. It is conceivable that COX2 induction, as part of a first line response, needs to be avoided to prevent (irreversible) DDD. COX2 expression 
was specifically observed in degenerate discs [46] and a correlation between DDD and cellular hypertrophy in the NP has been observed before [30]. In line with this thought: EGR1 was shown to be involved in repair of mesenchymal tissues [14, 15, 47]. It is of considerable interest to establish whether and when a hypertrophic response is initiated by these NP-nR cells and whether this is connected to loss of EGR1. A similar rational may be envisioned pertaining to keeping $T N F \alpha$ induction in check: this would prevent full blown release of COX2, MMP13, ADAMTS5 and Syndecan4 [48]. Despite the observed effects of EGR1 knock-down on transcriptional responses in NP cells, this data does not provide evidence for direct promoter binding of EGR1. Chromatin-immunoprecipitation analysis of EGR1-binding and specific histone modifications at these loci, as a function of response time, would shed additional light on their exact role in respect to the observed transcriptional response profiles.

\section{Relevance EGR1 signaling in vivo}

Classical genetic knock-out mice for EGR1 show no overt phenotype associated with bone and/or cartilage development, likely due to activation of functionally redundant mechanisms (e.g. EGR2-4) in vivo that compensate for loss of EGR1 function during development. When models of acute plasticity are interrogated however, EGR1 function becomes clear in vivo and in vitro. Following these strategies, it was established that EGR1 is important for adipogenesis and tenogenesis [13-15]. EGR1 (NGFI1, KROX24) and family members also mediate gene-environment interaction in the brain and is responsible for i.a. dendritic spine formation and synaptic plasticity and controls higher brain functions including movement, emotions, learning and memory [49-53]. Of relevance to the current study, EGR1 and EGR2 have been associated with inflammatory responses at multiple levels $[17-20,54]$. We find that EGR1 is responsible for anabolic and catabolic responses of distinct NP cell types. EGR1 was shown to inhibit ECM molecule production in chondrocytes exposed to TNF $\alpha$ [27]. We and others have also shown that EGR1 is required for tissue development and repair [16, 21, 22]. Combined, these observations stress the importance of IEGs in general and of EGR1 in particular in plastic biological systems. Identification of downstream signaling components within cell type-specific EGR1-dependent response pathways is expected to contribute to developing therapeutic strategies for e.g. degenerative disc disease.

\section{Conclusion}

EGR1 functions at the cross roads of inflammation and repair and represents an important response factor that allows NP cells to adapt to anabolic or catabolic stimuli. Well-defined cell models like the ones described herein will be imperative to study the role of specific cellular subtypes in degenerative disc disease and their potential use in cell-based disc regeneration strategies.

\section{Additional file}

\begin{abstract}
Additional file 1: Figure S1. Optimization of EGR1 knock-down using siRNA, A) cells were transfected with the indicated concentrations of siRNA against EGR1 mRNA (3, 30 and $100 \mathrm{nM}) .30 \mathrm{nM}$ and $100 \mathrm{nM}$ showed significant (*; $p<0.05$ ) reduction of EGR1 expression compared to siCTRL. B) Absence of off-target effects in siEGR1 treated cells. ERG1, EGR2 and EGR3 mRNA levels are depicted in siCTRL- and in siEGR1-treated cells. Only EGR1 mRNA levels were significantly reduced (*; $p<0.05)$. C) Sustained EGR1 knock-down: NP-nR (nR) and NP-R (R) cells were stimulated with ITS medium in the presence of control (CTRL; $30 \mathrm{nM})$ or EGR1 siRNA (EGR1; $30 \mathrm{nM}$ ); EGR1 protein expression was measured at 0, 2 and 48 hours post- stimulation in both cell lines. Beta Actin ( $B A C T$ ) was used as loading control; the indication $(\mathrm{t}+$ ) points to a relatively long apposition time. (TIF $59 \mathrm{~kb}$ )
\end{abstract}

\section{Abbreviations}

ADAMTS4: a disintegrin-like and metalloproteinase with thrombospondin type 1 motif 4; AF: annulus fibrosus; COL1A1: collagen type I, a1;

COL2A1: collagen type II, a1; COX2: cyclooxygenase 2; CYCLO: cyclophillin B; DDD: degenerative disc disease; ECM: extra cellular matrix; EGR1: early growth response factor 1; EIF2B1: eukaryotic translation initiation factor 2B, subunit 1; IEG: immediate early gene; IL-1ß: interleukin 1 beta;

IVD: intervertebral disc; KRT19: keratin 19; MMP3: matrix metalloproteinase 3; MRPL19: mitochondrial ribosomal protein L19; NC: notochordal cell; NFkB: nuclear Factor kappa B; NP: nucleus pulposus; NP-(n)R: NP(non)responder cells; siCTRL: scrambled siRNA (control); siEGR1: siRNA against EGR1 mRNA; SOX9: SRY-box 9; T: brachyury T; TNFa: tumor necrosis factor alpha; VCAN: versican; VPA: valproic acid; $\beta A C T$ : beta actin.

\section{Competing interests}

The authors declare that they have no competing interests.

\section{Authors' contributions}

GGHvdA contributed to conception and design of the study, acquisition, analysis and interpretation of data and drafting the article; SMR contributed to design of the study, analysis, handling and interpretation of data and drafting the article; RR-P contributed to acquisition of funding, data acquisition, analysis and interpretation of data; DAMS contributed to data acquisition and analysis, AC contributed to data acquisition and analysis, MFGAH contributed to data acquisition and analysis, MMC contributed to data acquisition and analysis, LWVR contributed to acquisition of funding, conception and design of the study, JAH contributed to design of the study, data handling and interpretation and drafting the article, TJMW contributed to conception and design of the study, data interpretation and drafting the article, JW contributed to acquisition of funding, conception and design of the study, data handling and interpretation and drafting the article, and was responsible for manuscript submission and correspondence. All authors have agreed to authorship for this manuscript and all authors have the appropriate permissions and rights to the reported data.

\section{Acknowledgements}

We thank Dr. Paul Willems for obtaining adult human IVD tissue for histology. This research forms part of the Project P2.01 IDiDAS of the research program of the BioMedical Materials institute, co-funded by the Dutch Ministry of Economic Affairs, Agriculture and Innovation. Additional Funding; LLP14 Grant Dutch Arthritis Foundation (JW, LWVR); Programme for Advanced Medical Education (RR-P), Fundação Calouste Gulbenkian, Fundação Champalimaud, Ministério da Saúde, Fundação para a Ciência e Tecnologia and Apifarma, Portugal (RR-P). None of the funding sources had any role in study design, data collection, analysis and interpretation, writing of the manuscript or the decision to submit the manuscript for publication.

\section{Author details}

${ }^{1}$ Department of Orthopaedic Surgery, Maastricht University Medical Centre, Maastricht, The Netherlands. ${ }^{2}$ Department of Molecular Genetics, Maastricht 
University Medical Centre, Maastricht, The Netherlands. ${ }^{3}$ Centre for Tissue Injury and Repair, Institute of Inflammation and Repair, The University of Manchester, Manchester, UK. ${ }^{4}$ NIHR Manchester Musculoskeletal Biomedical Research Unit, Manchester Academic Health Science Centre, Manchester, UK. ${ }^{5}$ Current Address: Department of Experimental Rheumatology, Radboud University Medical Center, Nijmegen, The Netherlands. ${ }^{6}$ Current Address: Department of Orthopaedics, Centro Hospitalar do Porto - Hospital de Santo António, Porto, Portugal.

\section{Received: 14 August 2015 Accepted: 9 March 2016}

\section{Published online: 14 March 2016}

\section{References}

1. Pattappa G, Li Z, Peroglio M, Wismer N, Alini M, Grad S. Diversity of intervertebral disc cells: phenotype and function. J Anat. 2012;221(6):480-96.

2. Dagenais S, Caro J, Haldeman S. A systematic review of low back pain cost of illness studies in the United States and internationally. Spine J. 2008;8:8-20.

3. Urban JP, Roberts S. Degeneration of the intervertebral disc. Arthritis Res Ther. 2003;5(3):120-30.

4. Sivakamasundari $V$, Lufkin T. Bridging the gap: understanding embryonic intervertebral disc development. Cell Dev Biol. 2012; 1(2).

5. Colombier P, Clouet J, Hamel O, Lescaudron L, Guicheux J. The lumbar intervertebral disc: from embryonic development to degeneration. Joint Bone Spine. 2014;81(2):125-9.

6. van den Akker GGH, Surtel DAM, Cremers A, Rodrigues-Pinto R, Richardson SM, Hoyland JA, van Rhijn LW, Welting TJM, Voncken JW. Novel immortal human cell lines reveal subpopulations in the nucleus pulposus. Arthritis Res Ther. 2014; 16(3):R135.

7. Goldring MB, Birkhead JR, Suen LF, Yamin R, Mizuno S, Glowacki J, Arbiser $J$, Apperley JF. Interleukin-1 beta-modulated gene expression in immortalized human chondrocytes. J Clin Invest. 1994;94(6):2307-16.

8. Risbud M, Guttapalli A, Tsai T, Lee J, Danielson K, Vaccaro A, Albert T, Gazit Z, Gazit D, Shapiro I. Evidence for skeletal progenitor cells in the degenerate human intervertebral disc. Spine. 2007;32(23):2537-44.

9. Sakai DMD, Mochida JMD, Yamamoto YMD, Toh EMD, Iwashina TMD, Miyazaki TMD, Inokuchi SMD, Ando KMD, Hotta TMD. Immortalization of human nucleus pulposus cells by a recombinant SV40 adenovirus vector: establishment of a novel cell line for the study of human nucleus pulposus cells. [Miscellaneous article]. Spine (Phila Pa 1976). 2004;29(14):1515-23.

10. Weiler C, Nerlich A, Schaaf R, Bachmeier B, Wuertz K, Boos N. Immunohistochemical identification of notochordal markers in cells in the aging human lumbar intervertebral disc. Eur Spine J. 2010;19(10):1761-70.

11. Liu MC, Chen WH, Wu LC, Hsu WC, Lo WC, Yeh SD, Wang MF, Zeng R, Deng WP. Establishment of a promising human nucleus pulposus cell line for intervertebral disc tissue engineering. Tissue Eng Part C Methods. 2013;20(1):1-10.

12. van den Akker GG, Surtel DA, Cremers A, Richardson SM, Hoyland JA, van Rhijn LW, Voncken JW, Welting TJ. Novel immortal cell lines support cellular heterogeneity in the human annulus fibrosus.PloS one 2016;11(1):e0144497.

13. Boyle KB, Hadaschik D, Virtue S, Cawthorn WP, Ridley SH, O'Rahilly S, Siddle $K$. The transcription factors Egr1 and Egr2 have opposing influences on adipocyte differentiation. Cell Death Differ. 2009;16(5):782-9.

14. Guerquin MJ, Charvet B, Nourissat G, Havis E, Ronsin O, Bonnin MA, Ruggiu M, Olivera-Martinez I, Robert N, Lu Y et al. Transcription factor EGR1 directs tendon differentiation and promotes tendon repair. J Clin Invest. 2013;123(8):3564-76.

15. Lejard V, Blais F, Guerquin MJ, Bonnet A, Bonnin MA, Havis E, Malbouyres M, Bidaud CB, Maro G, Gilardi-Hebenstreit $P$ et al. EGR1 and EGR2 involvement in vertebrate tendon differentiation. J Biol Chem. 2011;286(7):5855-67.

16. Spaapen F, van den Akker GG, Caron MM, Prickaerts P, Rofel C, Dahlmans VE, Surtel DA, Paulis Y, Schweizer F, Welting TJ et al. The immediate early gene product EGR1 and polycomb group proteins interact in epigenetic programming during chondrogenesis. PLoS One. 2013;8(3), e58083.

17. Nebbaki SS, El Mansouri FE, Afif H, Kapoor M, Benderdour M, Duval N, Pelletier JP, Martel-Pelletier J, Fahmi H. Egr-1 contributes to IL-1-mediated down-regulation of peroxisome proliferator-activated receptor gamma expression in human osteoarthritic chondrocytes. Arthritis Res Ther. 2012:14(2):R69.

18. Shin SY, Kim JH, Baker A, Lim Y, Lee YH. Transcription factor Egr-1 is essential for maximal matrix metalloproteinase- 9 transcription by tumor necrosis factor alpha. Mol Cancer Res. 2010;8(4):507-19.
19. Vincenti MP, Brinckerhoff CE. Early response genes induced in chondrocytes stimulated with the inflammatory cytokine interleukin-1beta. Arthritis Res. 2001;3(6):381-8.

20. Walters JN, Bickford JS, Newsom KJ, Beachy DE, Barilovits SJ, Herlihy JD, Nick HS. Regulation of human microsomal prostaglandin E synthase-1 by IL1 beta requires a distal enhancer element with a unique role for C/EBPbeta. Biochem J. 2012;443(2):561-71.

21. Reumann MK, Strachna O, Yagerman S, Torrecilla D, Kim J, Doty SB, Lukashova L, Boskey AL, Mayer-Kuckuk P. Loss of transcription factor early growth response gene 1 results in impaired endochondral bone repair. Bone. 2011:49(4):743-52.

22. Kurinna $\mathrm{S}$, Barton MC. Cascades of transcription regulation during liver regeneration. Int J Biochem Cell Biol. 2011;43(2):189-97.

23. Caron MM, Emans PJ, Surtel DA, Cremers A, Voncken JW, Welting TJ, van Rhijn LW. Activation of NF-kappaB/p65 facilitates early chondrogenic differentiation during endochondral ossification. PLoS One. 2012;7(3), e33467.

24. Szot P, White SS, Shen DD, Anderson GD. Valproic acid, but not lamotrigine, suppresses seizure-induced c-fos and c-Jun mRNA expression. Brain Res Mol Brain Res. 2005;135(1-2):285-9.

25. Okada A, Kushima K, Aoki Y, Bialer M, Fujiwara M. Identification of earlyresponsive genes correlated to valproic acid-induced neural tube defects in mice. Birth Defects Res A Clin Mol Teratol. 2005;73(4):229-38.

26. Decker EL, Nehmann N, Kampen E, Eibel H, Zipfel PF, Skerka C. Early growth response proteins (EGR) and nuclear factors of activated T cells (NFAT) form heterodimers and regulate proinflammatory cytokine gene expression. Nucleic Acids Res. 2003;31(3):911-21.

27. Rockel JS, Bernier SM, Leask A. Egr-1 inhibits the expression of extracellular matrix genes in chondrocytes by TNFalpha-induced MEK/ERK signalling. Arthritis Res Ther. 2009;11(1):R8.

28. Roberts S, Butler RC. Inflammatory mediators as potential therapeutic targets in the spine. Curr Drug Targets Inflamm Allergy. 2005;4(2):257-66.

29. Welting TJ, Caron MM, Emans PJ, Janssen MP, Sanen K, Coolsen MM, Voss L, Surtel DA, Cremers A, Voncken JW, et al. Inhibition of cyclooxygenase-2 impacts chondrocyte hypertrophic differentiation during endochondral ossification. Eur Cell Mater. 2011;22:420-36. discussion 436-427.

30. Rutges JP, Nikkels PG, Oner FC, Ottink KD, Verbout AJ, Castelein RJ, Creemers $L B$, Dhert WJ. The presence of extracellular matrix degrading metalloproteinases during fetal development of the intervertebral disc. Eur Spine J. 2010;19(8):1340-6.

31. Thiel G, Kaufmann K, Magin A, Lietz M, Bach K, Cramer M. The human transcriptional repressor protein NAB1: expression and biological activity. Biochim Biophys Acta. 2000;1493(3):289-301.

32. Svaren J, Sevetson BR, Apel ED, Zimonjic DB, Popescu NC, Milbrandt J. NAB2, a corepressor of NGFI-A (Egr-1) and Krox20, is induced by proliferative and differentiative stimuli. Mol Cell Biol. 1996;16(7):3545-53.

33. Srinivasan R, Mager GM, Ward RM, Mayer J, Svaren J. NAB2 represses transcription by interacting with the CHD4 subunit of the nucleosome remodeling and deacetylase (NuRD) complex. J Biol Chem. 2006;281(22):15129-37.

34. Silverman ES, Du J, Williams AJ, Wadgaonkar R, Drazen JM, Collins T. CAMPresponse-element-binding-protein-binding protein (CBP) and p300 are transcriptional co-activators of early growth response factor-1 (Egr-1). Biochem J. 1998;336(Pt 1):183-9.

35. Yu J, de Belle I, Liang $H_{1}$ Adamson ED. Coactivating factors p300 and CBP are transcriptionally crossregulated by Egr1 in prostate cells, leading to divergent responses. Mol Cell. 2004;15(1):83-94.

36. Weaver ICG, D'Alessio AC, Brown SE, Hellstrom IC, Dymov S, Sharma S, Szyf M, Meaney MJ. The transcription factor nerve growth factor-inducible protein A mediates epigenetic programming: altering epigenetic marks by immediate-early genes. J Neurosci. 2007;27(7):1756-68.

37. Nie Z, Hu G, Wei G, Cui K, Yamane A, Resch W, Wang R, Green Douglas Â R, Tessarollo L, Casellas R, et al. c-Myc is a universal amplifier of expressed genes in lymphocytes and embryonic stem cells. Cell. 2012;151(1):68-79.

38. Lin C, Y, Lovén J, Rahl Peter B, Paranal Ronald M, Burge Christopher B, Bradner James E, Lee Tong I, Young Richard A. Transcriptional amplification in tumor cells with elevated c-Myc. Cell. 2012;151(1):56-67.

39. Knoepfler PS, Zhang XY, Cheng PF, Gafken PR, McMahon SB, Eisenman RN. Myc influences global chromatin structure. Embo J. 2006;25(12):2723-34.

40. Narotsky MG, Francis EZ, Kavlock RJ. Developmental toxicity and structure-activity relationships of aliphatic acids, including doseresponse assessment of valproic acid in mice and rats. Fundam Appl Toxicol. 1994;22(2):251-65. 
41. Holmes LB. Teratogen-induced limb defects. Am J Med Genet. 2002;112(3):297-303.

42. Ehlers K, Sturje H, Merker HJ, Nau H. Valproic acid-induced spina bifida: a mouse model. Teratology. 1992;45(2):145-54.

43. Yu AE, Hewitt RE, Connor EW, Stetler-Stevenson WG. Matrix metalloproteinases. Novel targets for directed cancer therapy. Drugs Aging. 1997;11(3):229-44.

44. Muroski ME, Roycik MD, Newcomer RG, Van den Steen PE, Opdenakker G, Monroe HR, Sahab ZJ, Sang QX. Matrix metalloproteinase-9/gelatinase B is a putative therapeutic target of chronic obstructive pulmonary disease and multiple sclerosis. Curr Pharm Biotechnol. 2008:9(1):34-46.

45. Ruiz-Romero C, Blanco FJ. The role of proteomics in osteoarthritis pathogenesis research. Curr Drug Targets. 2009;10(6):543-56.

46. Hamamoto H, Miyamoto H, Doita M, Takada T, Nishida K, Kurosaka M. Capability of nondegenerated and degenerated discs in producing inflammatory agents with or without macrophage interaction. Spine (Phila Pa 1976). 2012;37(3):161-7.

47. Liu H, Zhu S, Zhang C, Lu P, Hu J, Yin Z, Ma Y, Chen X, OuYang H. Crucial transcription factors in tendon development and differentiation: their potential for tendon regeneration. Cell Tissue Res. 2014;1-12.

48. Fujita N, Gogate SS, Chiba K, Toyama Y, Shapiro IM, Risbud MV. Prolyl hydroxylase 3 (PHD3) modulates catabolic effects of tumor necrosis factor-alpha (TNF-alpha) on cells of the nucleus pulposus through co-activation of nuclear factor kappaB (NF-kappaB)/p65 signaling. J Biol Chem. 2012;287(47):39942-53.

49. Balamotis MA, Tamberg N, Woo YJ, Li J, Davy B, Kohwi-Shigematsu T, Kohwi Y. Satb1 ablation alters temporal expression of immediate early genes and reduces dendritic spine density during postnatal brain development. Mol Cell Biol. 2012;32(2):333-47.

50. Morice E, Farley S, Poirier R, Dallerac G, Chagneau C, Pannetier S, Hanauer A, Davis $\mathrm{S}$, Vaillend $\mathrm{C}$, Laroche $\mathrm{S}$. Defective synaptic transmission and structure in the dentate gyrus and selective fear memory impairment in the Rsk2 mutant mouse model of Coffin-Lowry syndrome. Neurobiol Dis. 2013;58:156-68.

51. Nunes AC, Duarte RB, Sousa TB, dos Santos JR, Freire MA, Costa MS. Expression of the immediate-early gene egr-1 and substance $P$ in the spinal cord following locomotor training in adult rats. Brain Res. 2010;1345:125-36.

52. Veyrac A, Gros A, Bruel-Jungerman E, Rochefort C, Kleine Borgmann FB, Jessberger S, Laroche S. Zif268/egr1 gene controls the selection, maturation and functional integration of adult hippocampal newborn neurons by learning. Proc Natl Acad Sci U S A. 2013;110(17):7062-7.

53. Xie L, Korkmaz KS, Braun K, Bock J. Early life stress-induced histone acetylations correlate with activation of the synaptic plasticity genes Arc and Egr1 in the mouse hippocampus. J Neurochem. 2013;125(3):457-64

54. Collins S, Lutz MA, Zarek PE, Anders RA, Kersh GJ, Powell JD. Opposing regulation of T cell function by Egr-1/NAB2 and Egr-2/Egr-3. Eur J Immunol. 2008:38(2):528-36.

\section{Submit your next manuscript to BioMed Central and we will help you at every step:}

- We accept pre-submission inquiries

- Our selector tool helps you to find the most relevant journal

- We provide round the clock customer support

- Convenient online submission

- Thorough peer review

- Inclusion in PubMed and all major indexing services

- Maximum visibility for your research

Submit your manuscript at www.biomedcentral.com/submit
Biomed Central 